\section{Curadoria em museus: múltiplos olhares}

\section{Por Marcio Rangel}

Doutor em História das Ciências e da

Saúde pela Fundação Oswaldo Cruz.

Pesquisador do Museu de Astronomia e Ciências Afins/MCT

(marciorangel@mast.br)

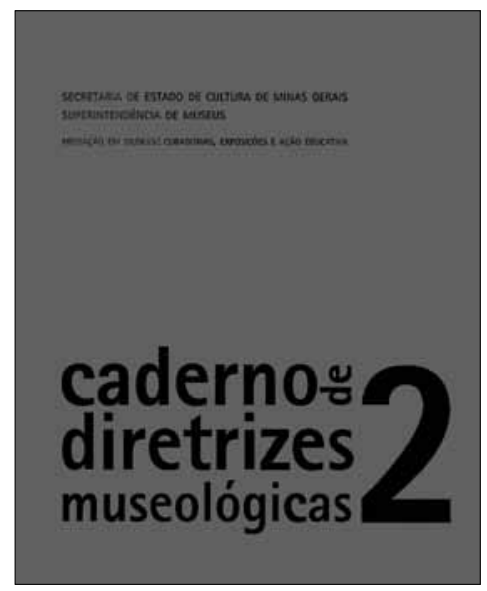

JULIÃO, Letícia; BITTENCOURT, José Neves (Orgs.) Caderno de Diretrizes Museológicas 2. Mediação em museus: curadorias, exposições, ação educativa. Belo Horizonte: Secretaria de Estado de Cultura de Minas Gerais/

Superintendência de Museus, 2008. 180p. : il.

O "Caderno de Diretrizes Museológicas 2 - Mediação em museus: curadorias, exposições, ação educativa", publicado pela Secretaria de Cultura de Minas Gerais através da Superintendência de Museus, tem por objetivo promover, a partir de uma perspectiva multidisciplinar, um debate sobre as diferentes abordagens relacionadas com a mediação museológica, com especial ênfase nos processos curatoriais desenvolvidos pelos museus. Os artigos reunidos no livro propõem novas reflexões e interpretações para este tema, que, com a complexidade de sua natureza, tem sido objeto de variadas discussões.

A principal intenção dos organizadores e autores que compõem o livro é dar visibilidade às múltiplas possibilidades da curadoria, neste caso, por meio de artigos que apresentam diferentes perspectivas de compreensão do tema e, em outros momentos, evidenciam percepções convergentes.

Além de um texto introdutório de José Neves Bittencourt, que analisa a etimologia da palavra curadoria e apresenta a estrutura da obra, os trabalhos foram organizados em três partes, sendo a primeira composta por três artigos, a segunda por oito artigos e a terceira por um vídeo.

O trabalho de abertura é de autoria de Cristina Bruno, que inicia sua discussão com a análise do percurso conceitual do termo curadoria, tendo como referencial um olhar sobre os "diferentes tempos históricos, distintos campos de conhecimento e múltiplos usos" (p. 15). Após indicar a difícil tarefa de mapear a trajetória do conceito de curadoria, Bruno estrutura seu artigo pontuando algumas perspectivas: os aspectos do percurso histórico do conceito de curadoria que geraram heranças relevantes para a atual proposta de definição; os matizes de sua ampliação contemporânea e os reflexos desta herança; o delineamento do perfil profissional do curador e o desenvolvimento do processo curatorial dentro dos museus. Bruno afirma que sua análise tem como base uma perspectiva museológica.

No artigo seguinte, Nelson Sanjad e Carlos Brandão definem curadoria "como o ciclo completo de atividades relativas aos acervos, compreendendo a execução ou a orientação da formação e desenvolvimento de coleções, segundo uma racionalidade pré-definida por uma política de acervos..." (p. 25). Podemos perceber nesta definição a influência da experiência profissional dos autores, ambos vinculados a museus com forte tradição na formação de coleções de história natural: Museu Paraense Emílio Goeldi e Museu de Zoologia da Universidade de São Paulo. O eixo central do artigo trata da relação da comunicação museológica com a política curatorial dos museus, priorizando os processos expositivos. Nesta análise, Sanjad e Brandão estruturam seus argumentos em três partes: a primeira apresenta a relação entre a história dos museus e o desenvolvimento dos acervos; nas seguintes, abordam a exposição como processo de comunicação, produtora de um discurso específico, incluindo neste processo a recepção do discurso pelos diferentes públicos.

Concluindo esta primeira parte da publicação, o artigo de Tereza Scheiner afirma que "não é possível tratar dos processos curatoriais sem, entretanto, definir que ideia de museu lhes serve de fundamento" (p. 36). Para Scheiner, 
a análise da trajetória do museu no quadro simbólico das diferentes sociedades é uma tarefa da Museologia, disciplina que, segundo a autora, "não tem como objeto de estudo os museus, ou a instituição museu, mas sim a ideia de museu desenvolvida em cada sociedade, em cada momento de sua história" (p. 40). De acordo com a autora, cabe à Museologia analisar as diferentes tipologias de museus atualmente existentes, "tratando de compreender em profundidade quais os contextos, razões e propósitos que as fundamentam, e buscando identificar como algumas delas se realizam hoje na sociedade contemporânea" (p. 43). Neste cenário, os processos curatoriais são compreendidos como "dispositivos técnicos, segundo os quais se realizam as funções intrínsecas a cada um destes tipos de museu" (p. 46).

A segunda parte da obra é aberta por Aline Montenegro e Francisco Régis, que analisam a curadoria de exposições em museus de história, mais especificamente no Museu Histórico Nacional e no Museu do Ceará. Os autores discutem os processos expositivos destas instituições e apresentam as diferentes possibilidades de abordagem de um tema histórico. Ressaltando a importância dos "indícios do passado", apontam para a importância da "elaboração de problemáticas históricas sobre as relações entre passado, presente e futuro" (p. 49). Montenegro e Régis problematizam a combinação de imagens, objetos, textos e outros recursos na elaboração das exposições, tendo em vista que, segundo os autores, "tudo indica que há uma dependência da escrita para se chegar a certos sentidos do objeto" (p. 68). Além das múltiplas possibilidades e desafios do processo curatorial em museus de história, o artigo também ressalta a importância do caráter educacional neste processo.

A partir do campo da arte, Roberto Condurú discute os principais traços característicos do fazer artístico e problematiza as formas de comunicação adotadas pelos salões, bienais e museus. Percebendo os curadores como intermediários nas relações entre as obras, os artistas e os públicos, o autor aponta para o papel de destaque deste personagem na estratificação dos agentes do campo artístico. De acordo com Condurú, uma característica marcante dos tempos atuais é a percepção da exposição de arte como "uma obra em si, com autorias, teorias, práticas e histórias" (p. 76). Sendo assim, torna-se fundamental o equilíbrio entre a exposição como obra e as obras de arte exibidas entre o curador e os demais autores envolvidos.

Em um outro campo e tendo como referencial as exposições de ciência e tecnologia, Cátia Rodrigues Barbosa reflete sobre a capacidade comunicativa desta tipologia de acervo e o papel exercido pelo curador neste processo de comunicação. Para Barbosa, o curador é um comunicador que cria elos entre o visitante e o objeto.

Ao descrever a implantação do Museu Municipal de Pains, Gilmar Henrique, Pablo de Oliveira Lima e Márcio Castro destacam o caráter multidisciplinar do projeto curatorial da instituição. Tendo o acervo arqueológico como eixo central de todas as discussões, os autores apresentam as diferentes categorias estabelecidas pelo projeto que orientaram a formação do acervo e a organização expositiva do museu: "artefatos líticos polidos; artefatos líticos lascados; artefatos de cerâmica; restos humanos e artefatos fabricados sobre material orgânico" (p. 97). Deve-se destacar que neste artigo os autores discutem um processo curatorial amplo, ou seja, da criação de um museu, considerando neste processo a formação de seu acervo, sua missão, sua exposição permanente/longa duração; sua estrutura física e organizacional.

No artigo seguinte, Cláudia Penha e Marcus Granato, ambos do Museu de Astronomia e Ciências Afins, optam por discutir o conceito de curadoria de acervos museológicos. Os autores definem esta curadoria como um processo que se inicia com a coleta e culmina com a divulgação e disseminação dos acervos. Ao longo do artigo, Santos e Granato, além de apresentarem "opiniões formuladas por diversos autores sobre o papel do curador e da curadoria de acervos" (p. 124), afirmam que "o que precisamos é uma abordagem do trabalho curatorial que reconheça o inter-relacionamento dos objetos, pessoas e 
sociedades, e expressem essa relação em contextos sociais e culturais" (p. 113).

Ao analisar o Museu Histórico Abílio Barreto, Thaís Velloso e Thiago Costa problematizam o papel das exposições como produto final dos museus. De acordo com os autores, mesmo que reconheçamos o papel de destaque exercido por este modelo de comunicação, devemos tornar evidente a "articulação solidária" (p. 129) existente entre todas as ações desenvolvidas pela instituição. Entre as atribuições do curador, os autores destacam a pesquisa como parte integrante de suas responsabilidades, pois esta possibilita o adensamento do tema ou conceito que irá nortear a estruturação da exposição.

Em uma outra perspectiva, mas com o mesmo objeto de análise, ou seja, o Museu Histórico Abílio Barreto, Célia Regina Alves e Nila Rodrigues discutem "as atividades práticas de avaliação, organização e tratamento técnico das informações de acervos formados por documentos cujo suporte é o papel, observando também a conservação física dos mesmos" (p. 145). No processo curatorial de documentos textuais e iconográficos, Alves e Rodrigues destacam três aspectos básicos: a compreensão do processo de formação da coleção em si; a obtenção das informações contidas nas unidades documentais; e a elaboração da documentação museológica.

O último artigo do "Caderno de Diretrizes Museológicas 2", de autoria de Magaly Cabral e Aparecida Rangel, aborda o tema da educação. Podemos afirmar que, de forma direta e indireta, esta questão transpassa todos os trabalhos desta publicação. Localizando a "curadoria educativa" dentro dos processos educativos definidos pelas instituições, as autoras afirmam que, assim como as demais curadorias abordadas nos artigos anteriores, a curadoria educativa também deve fazer parte do Plano Museológico (p. 165). De acordo com Cabral e Rangel, esta ação não estaria somente relacionada ao desenvolvimento de materiais complementares destinados a segmentos específicos de público, estendendo-se também aos processos de avaliação. Para as autoras, "a exposição deve ser um ponto de partida e não de chegada, na forma de comunicação com o público" (p. 168).

Com imagens de museus de diferentes regiões e variadas tipologias, o DVD que acompanha o livro apresenta de forma dinâmica e ilustrativa o depoimento de profissionais sobre curadoria. Apesar de ser estruturado em outra mídia e em outra linguagem, José Neves Bittencourt chama a atenção para o fato de que "o vídeo não é um complemento do livro” (p. 8). O mesmo deve ser considerado a terceira e última parte da publicação.

Finalizando, desejo destacar a contribuição desta obra para a prática curatorial desenvolvida nas instituições museológicas brasileiras. Os trabalhos apresentados nesta publicação enfatizam a necessidade de reinterpretar continuamente o próprio fazer expositivo e todas as ações derivadas desta prática. $\bigcirc$ "Caderno de Diretrizes Museológicas 2" é um convite reflexivo sobre um dos principais meios de comunicação dos museus. 